\title{
High-resolution seasonal snowfall simulation over Northeast China
}

\author{
YU EnTao ${ }^{1,2}$ \\ ${ }^{1}$ Nansen-Zhu International Research Center, Institute of Atmospheric Physics, Chinese Academy of Sciences, Beijing 100029, China; \\ ${ }^{2}$ Climate Change Research Center, Chinese Academy of Sciences, Beijing 100029, China
}

Received June 30, 2012; accepted October 18, 2012; published online November 30, 2012

Performance of the Weather Research and Forecasting (WRF) model in simulating seasonal snowfall over Northeast China was examined. The influences of horizontal resolution and physics parameterization schemes were also investigated. The results indicate that WRF can reasonably reproduce the main features of temperature and precipitation. The simulated spatial and temporal distribution of snowfall compared well with observations. Higher resolution simulations achieved better results, and WRF was found to be more sensitive to the choice of land surface and microphysics scheme than convective cumulus parameterization scheme.

Northeast China, seasonal snowfall, high-resolution simulation, WRF, physics parameterization scheme

Citation: $\quad$ Yu E T. High-resolution seasonal snowfall simulation over Northeast China. Chin Sci Bull, 2013, 58: 1412-1419, doi: 10.1007/s11434-012-5561-9

Recent global climate change and the subsequent impacts in terms of human adaptions are among the greatest challenges in modern times. While the warming trend is global, impacts of climate change are mainly experienced at the regional scale. Therefore, climate impact assessments, for both the present and future, primarily require regional- to local-scale climate data. However, most current operational weather forecasts systems cannot accurately simulate seasonal snowfall or snowpack, owing to their inability to resolve the necessary details of complex precipitation structures forced by mesoscale orography, land surface heterogeneities, and land-water contrasts. There are two ways to add value to global climate models (GCMs): statistical downscaling [1-5] and dynamical downscaling [6-9]. Regional climate models (RCMs) collectively represent one of the most effective approaches for adding fine-scale details to simulated climate change. For example, previous studies have indicated that RCMs could greatly improve simulations of monsoon precipitation compared to GCMs, mainly due to their higher resolution and more complex physical processes [10-12].

Intense snowfall events, which can bring heavy social

email: yetsyu@mail.iap.ac.cn and economic losses, represent the main type of meteorological disaster experienced in northeastern China (NEC) in winter, and the frequency and intensity of such events have increased markedly since the 1950 s [13,14]. Under the scenario of a warmer climate, intense snowfall events will still increase, mainly because of the acceleration of snowpack melting processes and evaporation, thus leading to enhanced water availability $[15,16]$. Therefore, research on snowfall events constitutes a major concern for meteorological science and policymakers, especially that involving high-resolution simulations.

Many previous studies have focused on intense snowfall, and their findings have provided us with a broad knowledgebase of the snowfall background circulation, formation and intensification processes [17-28]. However, most of this work has concentrated upon the background and synoptic analysis of special intense snowfall events; there is an absence in the literature of numerical simulations, and most studies have focused on the weather scale. Simulation of intense snowfall on the seasonal scale, although important and necessary, have been few, which is partly due to the coarse resolution and incompetence of existing numerical models.

Besides their horizontal resolution, many studies have 
revealed that current models are also quite sensitive to physics parameterization schemes, especially convective cumulus schemes [29-32]. Recent work has shown that land surface processes and microphysical schemes also play a comparatively important role [33]. Nevertheless, most physics parameterization studies have focused on rainfall, and less attention has been paid to snowfall.

This paper examines the performance of the Weather Research and Forecasting (WRF) model in simulating seasonal snowfall over NEC, and the associated influence of the model's configuration; namely, its horizontal resolution, as well as its land surface, microphysics and convective cumulus parameterization schemes. We attempt to address the following questions:

(1) How well does WRF perform in simulating seasonal snowfall event over NEC? Can this state-of-the-art numerical model reproduce the spatial and temporal distribution of seasonal snowfall over this region?

(2) What is the influence of horizontal resolution on snowfall simulation, and does a higher resolution mean better model performance?

(3) What influences does the physical parameterization scheme have on simulation ability?

\section{Model, data and experimental design}

Version 3.3.1 of the WRF model was used for the simulations carried out in the present study. The development of WRF is overseen by a collaborative effort among U.S. research groups, including the National Center for Atmospheric Research (NCAR), the National Centers for Environmental Prediction (NCEP), the Forecast Systems Labor- atory (FSL), the Air Force Weather Agency (AFWA), the Naval Research Laboratory, the University of Oklahoma, and the Federal Aviation Administration (FAA). It is widely used by weather forecasters and meteorological scientists for both weather and climate applications.

For the experiments in this study, we chose a large domain $(\mathrm{d} 01)$ of $142 \times 156$ grids $(\mathrm{W}-\mathrm{E} \times \mathrm{N}-\mathrm{S})$ with a horizontal resolution of $27 \mathrm{~km}$ (Figure 1), covering an area over central and eastern China. One reason for choosing such a domain was that it is well established from previous studies that the main sources of vapor for snowfall events during winter in NEC come from Southwest China and Inner Mongolia [18,20]. Another reason was that a larger domain can give WRF more freedom to develop its own synoptic and mesoscale circulations; i.e. it would increase the independence of the regional climate model from the driving data [34]. Nested inside d01, we chose a second domain (d02) with a resolution of $9 \mathrm{~km}$. The grid-size of d02 was $181 \times 187(\mathrm{~W}-\mathrm{E} \times \mathrm{N}-\mathrm{S})$, and it covered an area over NEC.

Four ensemble members were included in this study, and the main model configuration included the following parameterization schemes: WSM6 [35,36], LIN [37] and Thompson [38] (for microphysics); Kain-Fritsch [39,40] and Betts-Miller-Janjic [41,42] (for convective cumulus); Noah [43] and the RUC [44] (for land surface model); the CAM scheme for both short-wave and long-wave radiation [45]; and the YSU planet boundary layer scheme [46]. Table 1 summarizes the model configurations of the members.

Simulations over a 7-month period from 1 October through 1 May were conducted in the years 2009-2010. The first 5 days were considered as the spin-up period. The 6-h, 1.0-degree-grid FNL (Final) operational global analysis data provided the initial and lateral boundaryconditions for the

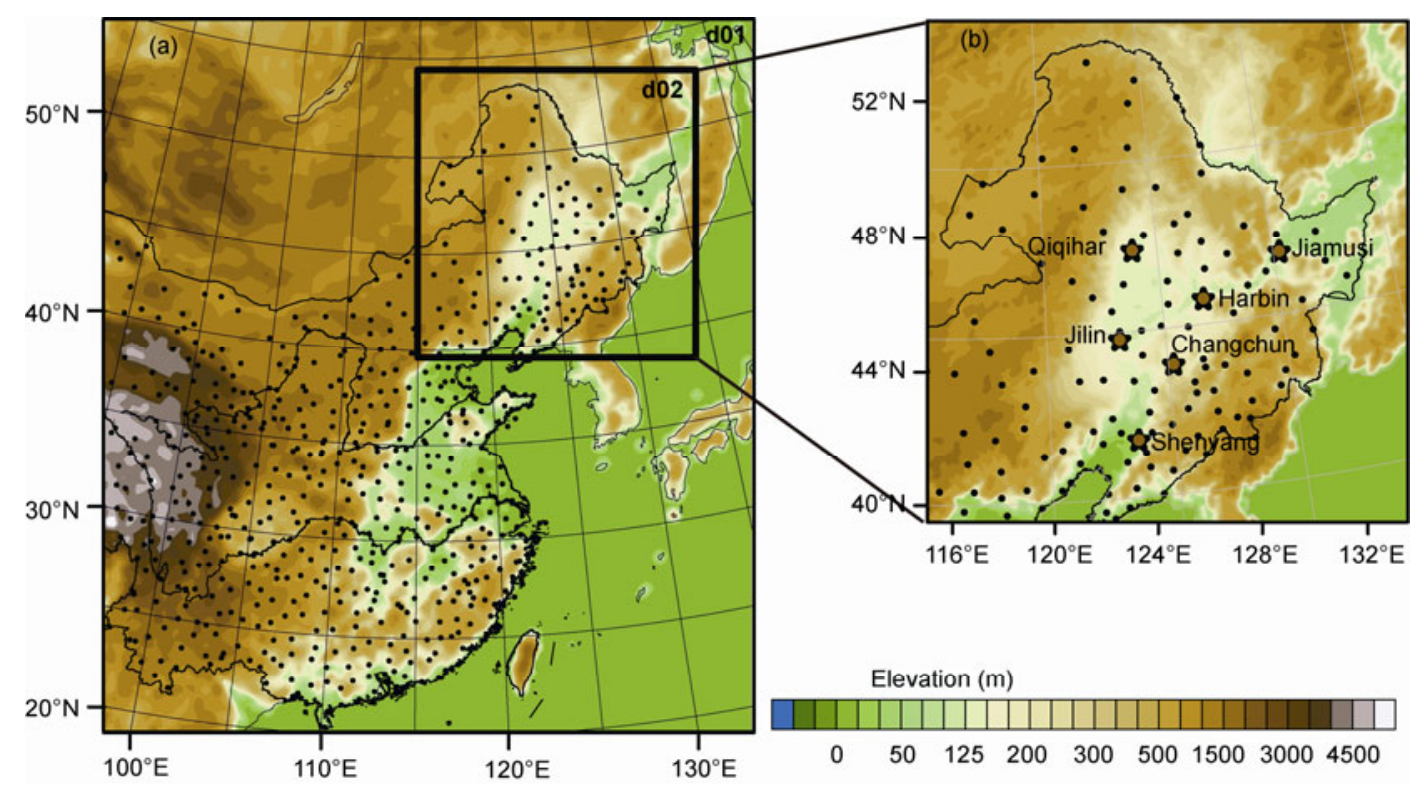

Figure 1 Model domain and location of observational sites (black dots) for (a) the full model domain and (b) a subdomain focused over NEC. Locations of some cities are indicated by stars in (b). 
Table 1 List of ensemble members with physics parameterizations

\begin{tabular}{lcccc}
\hline & E1 & E2 & E3 & E4 \\
\hline Microphysics scheme & WSM 6 & LIN & WSM6 & Thompson \\
Convective cumulus scheme & Betts-Miller-Janjic & Kain-Fritsch & Kain-Fritsch & Kain-Fritsch \\
Land surface model & NOAH & NOAH & NOAH & RUC \\
\hline
\end{tabular}

numerical experiments. SST data, deep soil temperature and green fraction data were updated every $12 \mathrm{~h}[7,20,47]$. Comparisons were made using observational temperature, precipitation and snowfall data, with temperature and snowfall data derived from station observations and rainfall data being 0.5 -degree-grid rain gauge data from the China Meteorological Administration (CMA).

\section{Results}

The focus of the present paper is to investigate the perfor-
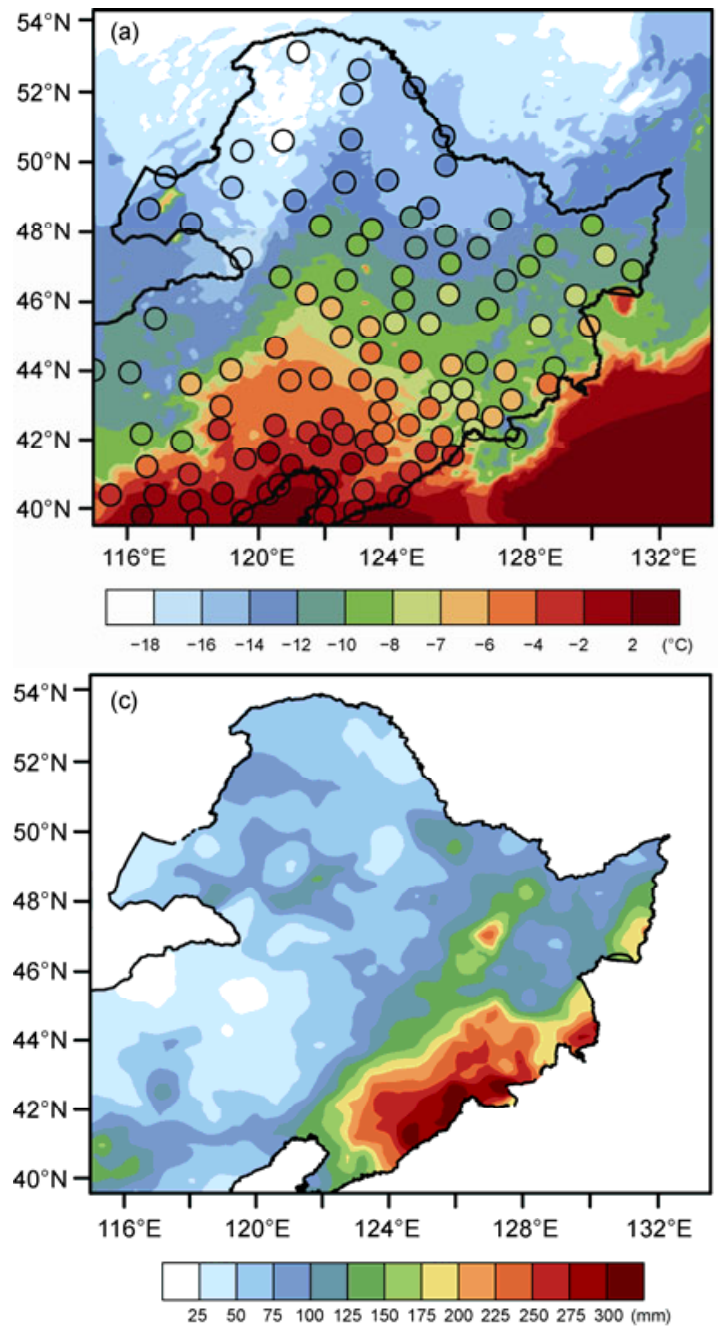

mance of WRF in simulating snowfall over NEC. Thus, we mainly analyze simulation and observation results from the inner domain $(\mathrm{d} 02)$.

\subsection{Temperature}

Figure 2(a) shows observed and simulated 7-month-averaged temperature distributions. From the observational data, we can see that temperature gradually decreased with latitude and altitude. In the region of Liaoning Province, the temperature was relatively higher than over Inner Mongolia, a feature that can largely be attributed to the presence of the
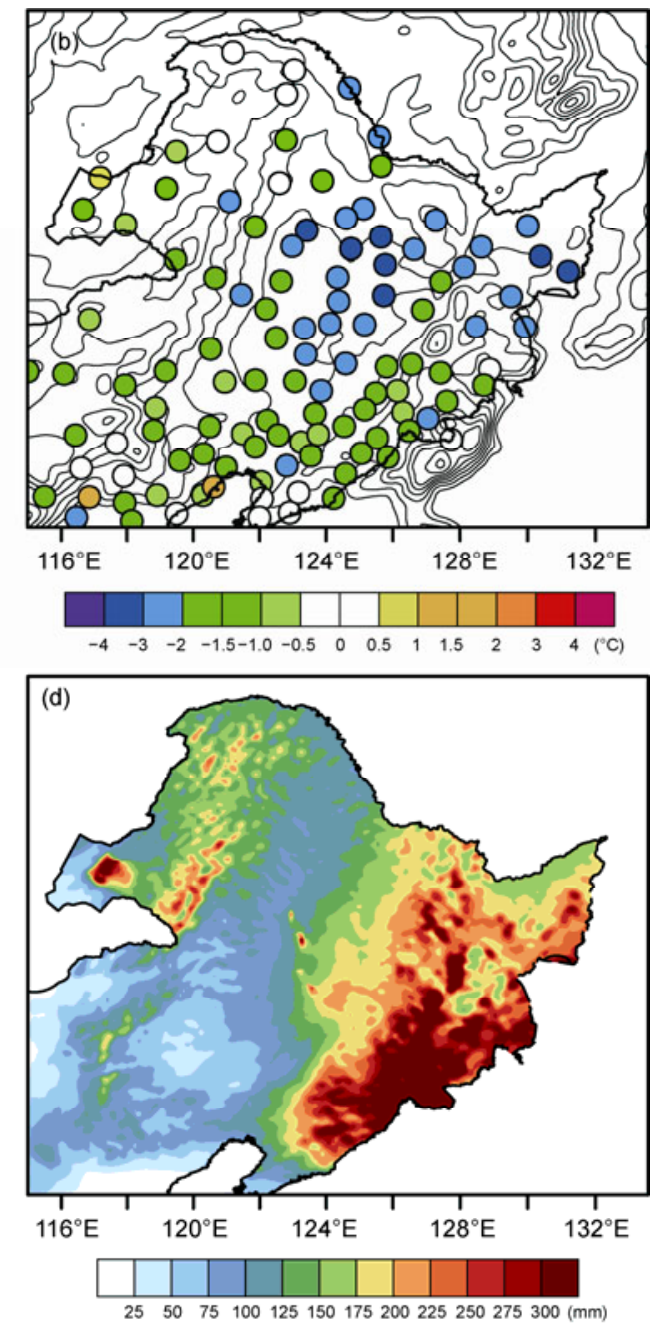

Figure 2 (a) Seven-month averaged temperature $\left({ }^{\circ} \mathrm{C}\right.$ ) from observation (circles) and model runs (shading) and (b) their differences. The extents of the differences are indicated using colored circles, with the meaning of the color given in the legend underneath. (c) Seven-month accumulated precipitation $(\mathrm{mm})$ from observation and (d) from WRF simulations. 
nearby warm ocean.

WRF was able to reasonably simulate the spatial distribution of temperature; the correlation coefficient was 0.93 , with confidence levels greater than $99 \%$. From the difference (Figure 2(b)), we can see that overall the model underestimated temperature, especially over high altitude regions. Over the region of Sanjiang Plain, for example, the level of underestimation was especially obvious.

\subsection{Precipitation}

Seven-month accumulated precipitation results from the model run and observations together with their relative differences are shown in Figure 2(c)-(d). The spatial pattern of cumulative precipitation from the model runs compares well with observations, with high values located over the southeastern part and mountainous areas of NEC. The spatial correlation coefficient was 0.77 , with confidence levels greater than $99 \%$. The model runs revealed more precipitation detail than observational data, owing to the higher horizontal resolution. The model-simulated precipitation results were higher than observed, especially over mountainous areas in northwestern NEC. The overestimation of the model was related to its inability to precisely catch the precipitation processes, as well as uncertainties in the observational data $[48,49]$. Over mountainous areas, the shortage of observation stations and uncertainties related to snowfall observation equipment adversely affected model-observation comparisons, thus demonstrating the importance of accurate measurements and a proper setup at observation stations.

\subsection{Seasonal snowfall (snow water equivalent)}

(i) Spatial pattern. The spatial distributions of 7-month accumulated snowfall from observation and model simulations are shown in Figure 3. As can be seen from the ob-

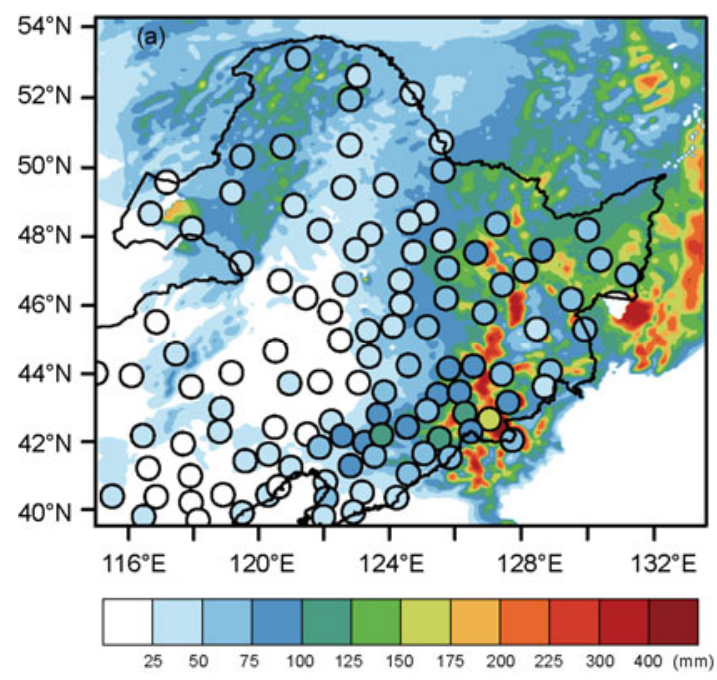

served data, the pattern was quite similar to that of precipitation, with high values in the southeastern part and mountainous areas of NEC. The simulated snowfall followed the observed results well, with a spatial correlation coefficient of 0.73 , at confidence levels greater than $99 \%$. Meanwhile, greater detail relating to snowfall distribution could be found in the WRF simulation, especially for orographic snowfall in eastern NEC. The model-simulated snowfall was higher in northern NEC, but lower in southern NEC, compared to observations. In the central part of NEC, simulated results compared well with observed data, with a relative error of less than $25 \%$. The regions with higher snowfall in Figure 3(b) reflect closely the cooler areas in Figure 2(b), indicating a significant relationship between snowfall and temperature. Lower temperatures are favorable for the formation and intensification of snowfall.

(ii) Temporal distribution. Figure 4(a) shows daily snowfall amounts from observation stations in d02 (i.e. observed results), along with the average of four retrospective simulations. The daily snowfall amount is the sum of all the stations. The main temporal feature revealed from the observed data is a bimodal distribution, with more snowfall in late autumn and early spring, and less in winter. The simulated results reflect this feature well, with a spatial correlation coefficient of 0.93 , at confidence levels greater than 99\%. Furthermore, simulated extreme snowfall events compared well with observation, indicating WRF did a good job in this regard.

\subsection{Impacts of horizontal resolution}

To investigate the impacts of horizontal resolution on WRFsimulated snowfall accumulation, the daily time series of accumulated snowfall based on 9- and $27-\mathrm{km}$ grid spacing simulations over the same domain (d02) is shown in Figure 5. As can be seen from these data, the 9- and 27-km simulations

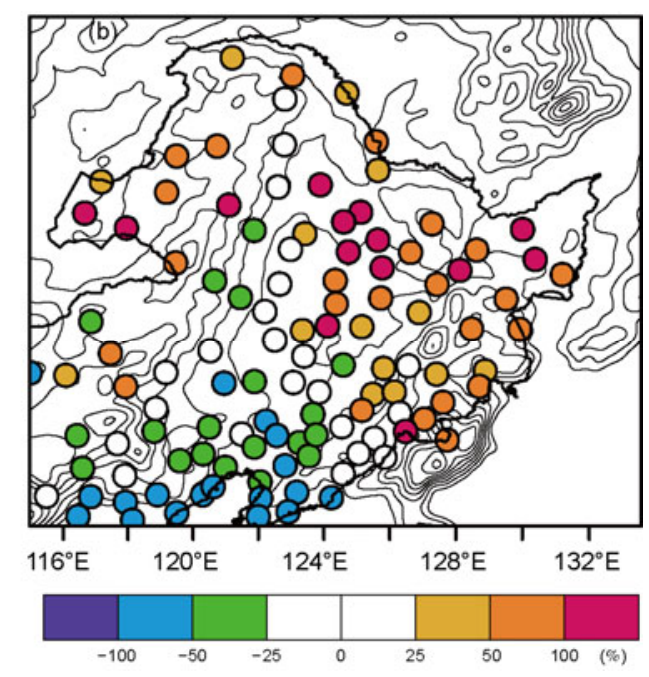

Figure 3 Same as in Figure 2(a) and (b), but for snow water equivalent (mm). 


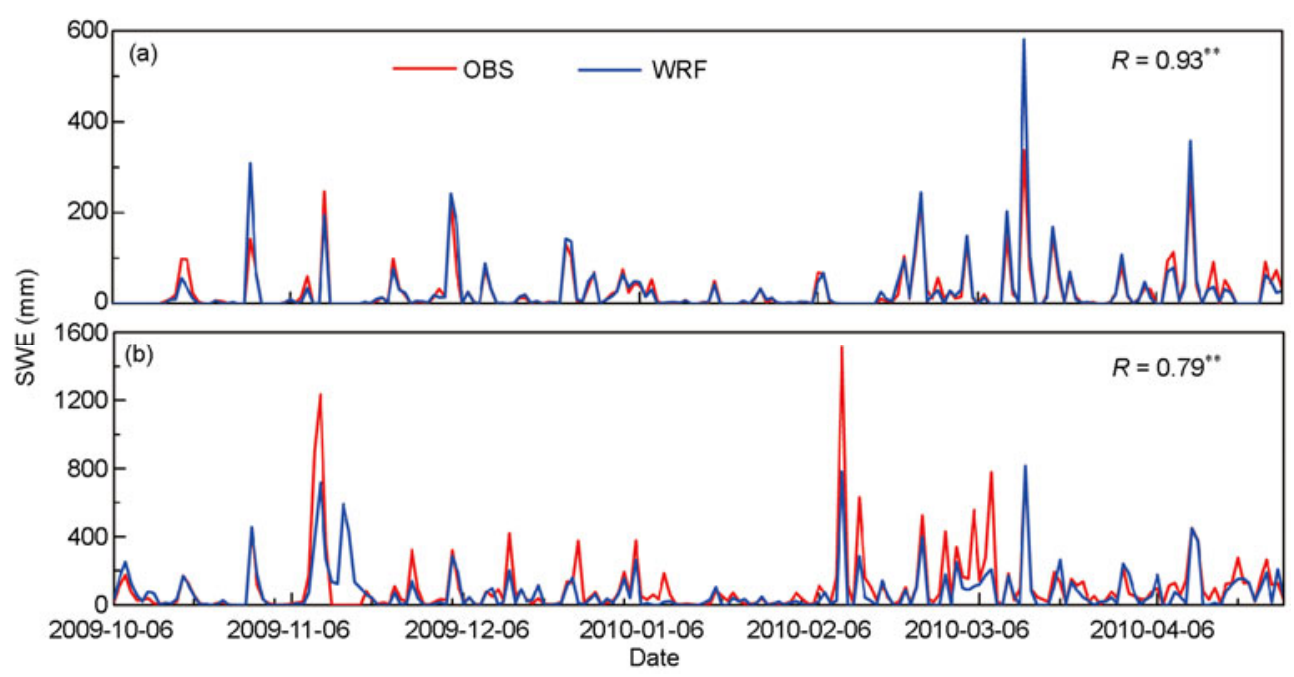

Figure 4 Daily time series of snowfall amount (mm) for (a) 9-km- and (b) 27-km-grid simulations. The daily amount is the sum of station snowfall inside each domain.

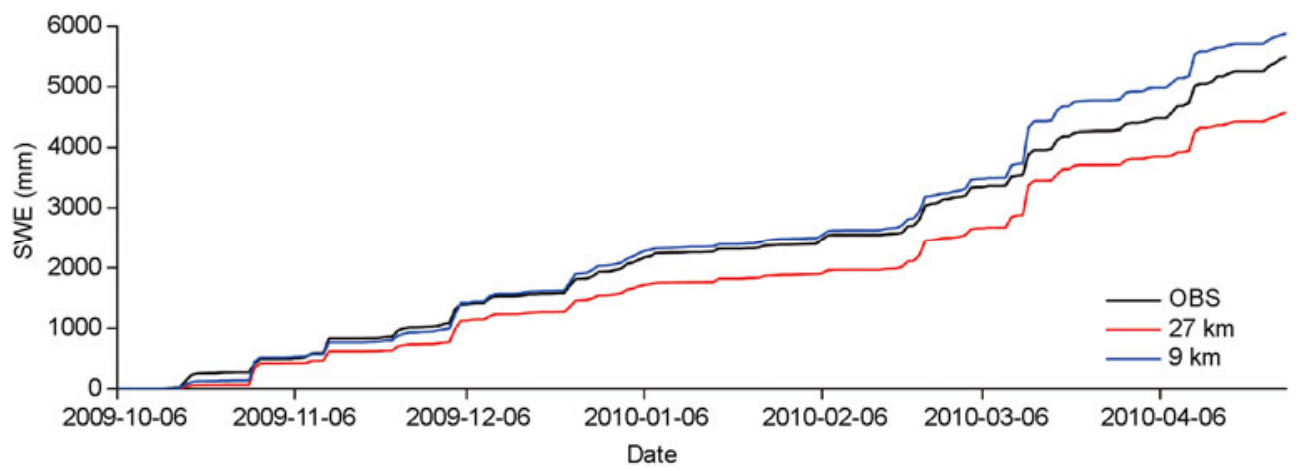

Figure 5 Time series of accumulated snowfall amount ( $\mathrm{mm}$ ) for stations in the same domain (d02): observed (black line) and model simulations (red and blue lines).

followed observed results well, with spatial correlation coefficients of 0.93 and 0.91 respectively, at confidence levels greater than $99 \%$. However, the $27-\mathrm{km}$ model run result was overall lower than observation; the underestimation was quite obvious during the 7-month period. The 9-km simulation compared well with observation, except for an overestimation of intense snowfall in the middle of March (Figure 4(a)). The comparison indicates that an increasing level of snowfall as the model resolution increases is evident in WRF simulations.

The daily time series of snowfall amount based on 27-km grid spacing simulations over the outer domain (d01) was also investigated, and the results are shown in Figure 4(b). Simulated results were lower than observed, especially for extreme snowfall events. A comparison between Figure 4(a) and (b) indicates that better performance can be achieved with higher horizontal resolution.

\subsection{Impact of physics parameterizations}

In the simulations reported upon thus far, two land-surface, three microphysics, and two cumulus convection parameterization schemes were used. A series of experiments using different combinations of schemes were also conducted to investigate the impact of physics parameterizations on WRF simulation. Unlike the previous simulations, which were run under 9- and 27-km grid spacings, these simulations focused on the outer domain (d01). The results of each physics parameterization scheme were ensemble means of all the experiments that contained the scheme in question. For example, the result based on Noah was the ensemble mean of the LBN, TBN, WBN, LKN, TKN and WKN experiments listed in Table 2.

The impacts of physics parameterizations were more readily discerned by listing the model averages, biases and spatial correlation coefficients of all stations, as shown in Table 3. To calculate the average amount simulated by WRF, the result of the nearest grid to the observation station was selected as the model result. Obvious model dependence on physics parameterization schemes can be seen from Table 3; however, we cannot find one experiment that was best among all the experiments in all aspects. WBN, WKN 
Table 2 List of numerical experiments with various physics parameterizations

\begin{tabular}{lcll}
\hline Expt & Land surface & Microphysics & Cumulus convective \\
\hline LBN & Noah & Lin & Betts-Miller-Janjic \\
TBN & Noah & Thompson & Betts-Miller-Janjic \\
WBN & Noah & WSM6 & Betts-Miller-Janjic \\
LKN & Noah & Lin & Kain-Fritsch \\
TKN & Noah & Thompson & Kain-Fritsch \\
WKN & Noah & WSM6 & Kain-Fritsch \\
LBR & RUC & Lin & Betts-Miller-Janjic \\
TBR & RUC & Thompson & Betts-Miller-Janjic \\
WBR & RUC & WSM6 & Betts-Miller-Janjic \\
LKR & RUC & Lin & Kain-Fritsch \\
TKR & RUC & Thompson & Kain-Fritsch \\
WKR & RUC & WSM6 & Kain-Fritsch \\
\hline
\end{tabular}

Table 3 Comparison of model averages, biases and spatial correlation coefficients of the experiments ${ }^{\text {a) }}$

\begin{tabular}{lcrcc}
\hline Expt & $\begin{array}{c}\text { Average } \\
(\mathrm{mm})\end{array}$ & $\begin{array}{c}\text { Bias } \\
(\mathrm{mm})\end{array}$ & $\begin{array}{c}\text { Relative bias } \\
(\%)\end{array}$ & $\begin{array}{c}\text { Correlation } \\
\text { coefficient }\end{array}$ \\
\hline OBS & 26.18 & - & - & - \\
LBN & 24.8 & -1.37 & -5.25 & $0.89^{* *}$ \\
TBN & 13.03 & -13.14 & -50.22 & $0.72^{*}$ \\
WBN & 32.73 & 6.55 & 25.04 & $0.91^{*}$ \\
LKN & 25.41 & -0.76 & -2.92 & $0.89^{* *}$ \\
TKN & 20.44 & -5.74 & -21.92 & $0.84^{* *}$ \\
WKN & 31.8 & 5.62 & 21.49 & $0.9^{* *}$ \\
LBR & 22.12 & -4.05 & -15.48 & $0.88^{* *}$ \\
TBR & 14.55 & -11.63 & -44.43 & $0.82^{* *}$ \\
WBR & 59.55 & 33.37 & 127.49 & $0.9^{* *}$ \\
LKR & 22.3 & -3.88 & -14.82 & $0.88^{* *}$ \\
TKR & 18.41 & -7.76 & -29.66 & $0.8^{* *}$ \\
WKR & 53.09 & 26.91 & 102.82 & $0.89^{* *}$ \\
\hline
\end{tabular}

a) $*,>95 \%$ confidence level; $* *,>99 \%$ confidence level.

and WBR showed better performance in terms of their spatial correlation coefficients; LBN and LKN were better in terms of relative bias; while for snowfall accumulation LBN and LKN were relatively better, and TBN, WBR and WKR were relatively worse.

A comparison of time series of accumulated snowfall amounts for different physics parameterization schemes is shown in Figure 6. From the land surface model series experiments (Figure 6(a)), we can see that Noah reflected observations very well, while RUC greatly overestimated snowfall amounts. From Figure 6(b) we can see that the simulation from Lin followed the observed data well, that WSM6 showed an obvious overestimation, and that Thompson underestimated compared to observations. BettsMiller-Janjic and Kain-Fritsch were quite similar to each other, with little overestimation. The WRF model showed an obvious dependence on physics parameterization schemes, and is more sensitive to microphysics and land surface schemes compared to the choice of convective cumulus parameterization scheme. The strong sensitivity to micro-
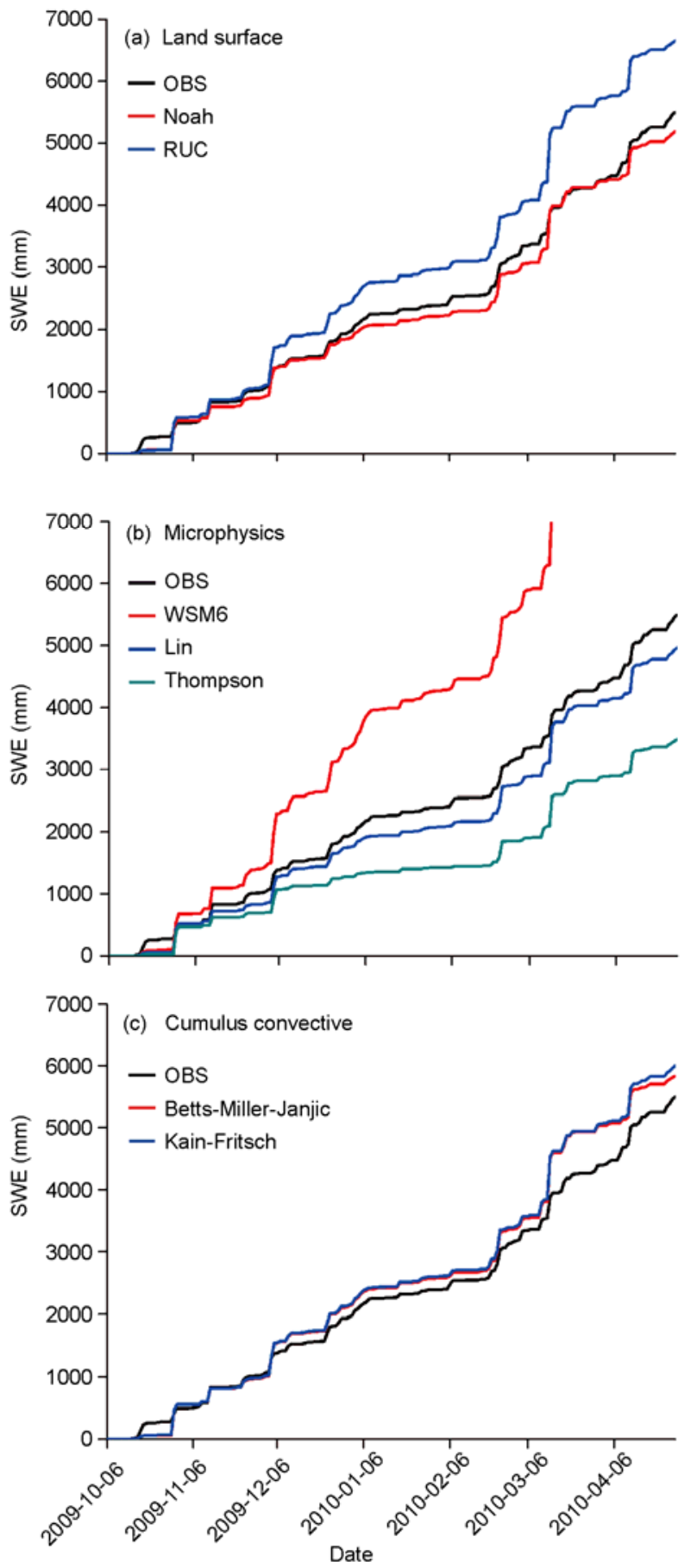

Figure 6 Comparison of time series of accumulated snowfall amount $(\mathrm{mm})$ for stations over the same domain (d01): observed (black line) and simulated (red and blue lines).

physics and land surface schemes largely results from land surface coupling and ice-phase microphysical processes $[33,50]$, all of which, in turn, influence snowfall simulation.

\section{Conclusions}

This study examined the performance of the WRF model in 
simulating seasonal snowfall over NEC. The influences of horizontal resolution and parameterization schemes were investigated. The results indicate that WRF can reasonably reproduce the main features of temperature and precipitation. The spatial and temporal distribution of snowfall can also be well reproduced. However, an underestimation of temperature and an overestimation of precipitation were found, and these uncertainties in simulation indicate the importance of high-resolution observation data [51]. A higher resolution can achieve better model performance, and WRF was found to be more sensitive to the choice of microphysics parameterization scheme and land surface model compared to the convective cumulus parameterization scheme used when simulating seasonal snowfall. Noah and Lin showed better performance among the physics schemes.

This work was supported by the National Natural Science Foundation of China (41130103), the Major State Basic Research Development Program of China (2012CB955401), and the CAS-CSIRO Cooperative Research Program (GJHZ1223). The observed temperature and precipitation data were supplied by the China Meteorological Data Sharing Service System (http://cdc.cma.gov.cn), and the observed snowfall data were provided by CHEN LiJuan of the National Climate Center, China Meteorological Administration.

1 Sun J Q, Ahn J B. A GCM-based forecasting model for the landfall of tropical cyclones in China. Adv Atmos Sci, 2011, 28: 1049-1055

2 Wang H J, Fan K. A new scheme for improving the seasonal prediction of summer precipitation anomalies. Weather Forecast, 2009, 24: $548-554$

3 Sun J Q, Chen H P. Predictability of western North Pacific typhoon activity and its factors using DEMETER coupled models. Chin Sci Bull, 2011, 56: 3474-3479

4 Fan K. A prediction model for Atlantic named storm frequency using a year-by-year increment approach. Weather Forecast, 2010, 25: 1842-1851.

5 Sun J Q, Chen H P. A statistical downscaling scheme to improve global precipitation forecasting. Meteor Atmos Phys, 2012, doi: 10.1007/s00703-012-0195-7

6 Ju L X, Wang H J. Modern climate over East Asia simulated by a regional climate model nested in a global gridpoint general circulation model. Chin J Geophys, 2006, 49: 52-60

7 Yu E T, Wang $\mathrm{H} \mathrm{J}$, Sun J Q. A Quick report on a dynamical downscaling simulation over China using the Nested Model. Atmos Oceanic Sci Lett, 2010, 3: 325-329

8 Gao X J, Xu Y, Zhao Z C, et al. On the role of resolution and topography in the simulation of East Asia precipitation. Theor Appl Climatol, 2006, 6: 173-185

9 Zhang D F, Gao X J, Ouyang L. Simulation of present climate over China by a regional climate model. J Trop Meteorol, 2008, 14: 19-23

10 Gao X J, Shi Y, Song R, et al. Reduction of future monsoon precipitation over China: Comparison between a high resolution RCM simulation and the driving GCM. Meteorol Atmos Phys, 2008, 100: 73-86

11 Liu H B. Numerical simulation of the heavy rainfall in the Yangtze-Huai River Basin during summer 2003 using the WRF Model. Atmos Oceanic Sci Lett, 2012, 5: 20-25

12 Li Q P, Ding Y H. Multi-year simulation of the east asian monsoon and precipitation in china using a regional climate model and evaluation (in Chinese). Acta Meteorol Sin, 2004, 62: 140-153

13 Sun J Q, Wang H J, Yuan W, et al. Spatial-temporal features of intense snowfall events in China and their possible change. J Geophys Res, 2010, 116: D16110

14 Liu Y L, Yu H M, Ren G Y, et al. Temporal and spatial variation characteristics of the snow storms in Heilongjiang Province during 1961-2006 (in Chinese). Clim Environ Res, 2010, 15: 470-478

15 Rasmussen R, Liu C H, Ikeda K, et al. High-resolution coupled climate runoff simulations of seasonal snowfall over Colorado: A process study of current and warmer climate. J Clim, 2011, 24: 30153048

16 Chen H P, Sun J Q, Chen X L, et al. CGCM projections of heavy rainfall events in China. Int J Climatol, 2012, 32: 441-450

17 Zhang X L, Cheng L S. Dynamic diagnoses of the genesis and development for the mesoscale shear line during "96.1" snowstorm. II: diagnoses of vorticity and vorticity variability (in Chinese). Plateau Meteorol, 2000, 19: 285-294

18 Sun J Q, Wang H J, Yuan W. A preliminary investigation on causes of the catastrophic snowstorm in March, 2007 in the northeastern parts of China (in Chinese). Acta Meteorol Sin, 2009, 67: 469-477

19 Wang H J, Sun J Q, Chen H P, et al. Extreme climate in China: Facts, simulation and projection. Meteorol Z, 2012, doi: 10.1127/09412948/2012/0330

20 Wang H J, Yu E T, Yang S. An exceptionally heavy snowfall in Northeast China: Large-scale circulation anomalies and hindcast of the NCAR WRF model. Meteorol Atmos Phys, 2011, 113: 11-25

21 Zhao S X, Sun J H, Chen H, et al. A Study on snowfall in Beijing on 7 December 2001 (in Chinese). Clim Environ Res, 2002, 7: 7-21

22 Liu A, Moore G W K. Lake-effect snowstorms over southern Ontario, Canada, and their associated synoptic-scale environment. Mon Weather Rev, 2004, 132: 2595-2609

23 Wang C H, Wang Z L, Cui Y. Snow cover of China during the last 40 years: Spatial distribution and interannual variation (in Chinese). J Glaciol Geocryol, 2009, 31: 301-310

24 Wang H J, Sun J Q. Variability of Northeast China river break-up Date. Adv Atmos Sci, 2009, 26: 701-706

25 Liu J P, Curry J A, Wang H J, et al. Impact of declining Arctic sea ice on winter snowfall. Proc Natl Acad Sci USA, 2012, 109: 4074-4079

26 Shi Y, Gao X J, Wu J, et al. Changes in snow cover over China in the 21st century as simulated by a high resolution regional climate model. Environ Res Lett, 2011, 6: 045401

27 Qin D H, Liu S Y, Li P J. Snow cover distribution, variability, and response to climate change in western China. J Clim, 2006, 19: 18201833

28 Li P J. Response of Tibetan snow cover to global warming (in Chinese). Acta Geogr Sin, 1996, 51: 260-265

29 Dutra E, Kotlarski S, Viterbo P, et al. Snow cover sensitivity to horizontal resolution, parameterizations, and atmospheric forcing in a land surface model. J Geophys Res, 2011, 116: 16

30 Flaounas E, Bastin S, Janicot S. Regional climate modelling of the 2006 West African monsoon: Sensitivity to convection and planetary boundary layer parameterisation using WRF. Clim Dyn, 2011, 36: 1083-1105

31 Awan N K, Truhetz H, Gobiet A. Parameterization-induced error characteristics of MM5 and WRF operated in climate mode over the Alpine region: An ensemble-based analysis. J Clim, 2011, 24: 31073123

32 Yu E T, Wang H J, Gao Y Q, et al. Impacts of cumulus convective parameterization schemes on summer monsoon precipitation simulation over China. Acta Meteorol Sin, 2011, 25: 581-592

33 Liu C H, Ikeda K, Thompson G, et al. High-resolution simulations of wintertime precipitation in the Colorado headwaters region: Sensitivity to physics parameterizations. Mon Weather Rev, 2011, 139: 3533-3553

34 Heikkila U, Sandvik A, Sorteberg A. Dynamical downscaling of ERA-40 in complex terrain using the WRF regional climate model. Clim Dyn, 2011, 37: 1551-1564

35 Dudhia J, Hong S Y, Lim K S. A new method for representing mixed-phase particle fall speeds in bulk microphysics parameterizations. J Meteorol Soc Jpn, 2008, 86: 33-44

36 Hong S Y, Lim J. The WRF single-moment 6-class microphysics scheme (WSM6). J Korean Meteorol Soc, 2006, 42: 129-151

37 Lin Y L, Farley R D, Orville H D. Bulk parameterization of the snow field in a cloud model. J Clim Appl Meteorol, 1983, 22: 1065-1092 
38 Thompson G, Rasmussen R, Manning K. Explicit forecasts of winter precipitation using an improved bulk microphysics scheme. Part I: Description and sensitivity analysis. Mon Weather Rev, 2004, 132: 519-542

39 Kain J. The Kain-Fritsch convective parameterization: An update. J Appl Meteorol, 2004, 43: 170-181

40 Kain J, Fritsch J. Convective parameterization for mesoscale models: The Kain-Fritsch scheme. The representation of cumulus convection in numerical models. Meteorol Monogr, 1993, 46: 165-170

41 Betts A K, Miller M J. A new convective adjustment scheme. Part II: Single column tests using GATE wave, BOMEX, ATEX and arctic air mass data sets. Quart J Roy Meteorol Soc, 1986, 112: 693-709

42 Janjic Z I. The step-mountain Eta coordinate model: Further developments of the convection, viscous sublayer, and turbulence closure schemes. Mon Weather Rev, 1994, 122: 927-945

43 Chen F, Dudhia J. Coupling an advanced land surface-hydrology model with the Penn State-NCAR MM5 modeling system. Part I: Model implementation and sensitivity. Mon Weather Rev, 2001, 129: 569-585

44 Smirnova T G, Brown J M, Benjamin S G, et al. Parameterization of cold-season processes in the MAPS. J Geophys Res, 2000, 105:
4077-4086

45 Collins W, Rasch P, Boville B, et al. Description of the NCAR community atmosphere model (CAM 3.0). NCAR Tech. Note NCAR/ TN-464+ STR, 2004

46 Hong S Y, Noh Y, Dudhia J. A new vertical diffusion package with an explicit treatment of entrainment processes. Mon Weather Rev, 2006, 134: 2318-2341

47 Yu E T, Wang H J, Sun J Q, et al. Climatic response to changes in vegetation in the Northwest Hetao Plain as simulated by the WRF model. Int J Climatol, 2012, doi: 10.1002/joc.3527

48 Shi Y, Gao X J, Wu J, et al. Simulating future climate changes over North China with a high resolution regional climate model (in Chinese). J Appl Meteorol Sci, 2010, 21: 580-589

49 Wu J, Gao X J, Shi Y, et al. Climate change over Xinjiang region in the 21 st century simulated by a high resolution regional climate model (in Chinese). J Glaciol Geocryol, 2011, 33: 479-487

50 Ikeda K, Rasmussen R, Liu C H, et al. Simulation of seasonal snowfall over Colorado. Atmos Res, 2010, 97: 462-477

$51 \mathrm{Xu} \mathrm{Y,} \mathrm{Gao} \mathrm{X} \mathrm{J,} \mathrm{Shen} \mathrm{Y,} \mathrm{et} \mathrm{al.} \mathrm{A} \mathrm{daily} \mathrm{temperature} \mathrm{dataset} \mathrm{over} \mathrm{China}$ and its application in validating a RCM simulation. Adv Atmos Sci, 2009, 26: 763-772

Open Access This article is distributed under the terms of the Creative Commons Attribution License which permits any use, distribution, and reproduction in any medium, provided the original author(s) and source are credited. 